\title{
Students' Attitudes toward Plagiarism in the Interior Design Field
}

\author{
Abeer A. Alawad \\ Department of Interior Design and Furniture, Faculty of Human Sciences and Design, King Abdulaziz University, Jeddah, Saudi Arabia
}

Received April 10, 2021; Revised May 24, 2021; Accepted June 15, 2021

\section{Cite This Paper in the following Citation Styles}

(a): [1] Abeer A. Alawad , "Students' Attitudes toward Plagiarism in the Interior Design Field," Civil Engineering and Architecture, Vol. 9, No. 4, pp. 1179-1188, 2021. DOI: 10.13189/cea.2021.090419.

(b): Abeer A. Alawad (2021). Students' Attitudes toward Plagiarism in the Interior Design Field. Civil Engineering and Architecture, 9(4), 1179-1188. DOI: 10.13189/cea.2021.090419.

Copyright $(\mathrm{C} 2021$ by authors, all rights reserved. Authors agree that this article remains permanently open access under the terms of the Creative Commons Attribution License 4.0 International License

\begin{abstract}
Plagiarism is an important issue, with which students need to get acquainted before they start practicing as professionals after graduation. This study aimed to identify students' attitudes towards plagiarism in the interior design field. It identified three aspects of visual plagiarism according to students' perceptions: students' knowledge and understanding of the topic, causes of plagiarism, and the time when plagiarism typically occurs during a project. The participants were interior design and furniture students $(n=59)$ from King Abdulaziz University, Jeddah, Saudi Arabia. Data were collected through a questionnaire. The results revealed that students understand the general meaning of plagiarism but lack clarity regarding its finer details in the field of interior design. Five reasons, related to accidental plagiarism, were found to drive student to plagiarize. Furthermore, coping was most likely to occur in specific project phases. This study provides information that will help facilitate better practices for preventing visual plagiarism in various artistic fields. It will also make faculty members aware of students' perceptions of plagiarism in the field of interior design, along with the need to include this issue in the curriculum to ensure academic integrity, foster creativity, and provide a clear understanding of plagiarism before students commence their professional careers.
\end{abstract}

Keywords Plagiarism, Interior Design, Students' Perceptions, Visual Plagiarism, Academic Integrity, Higher Education

\section{Introduction}

Ethical practices are expected to be followed by every professional. "Ethics" has multiple definitions, and ethical theories go back to the days of Aristotle, who developed one of the most influential philosophies regarding the same [1]. An important ethical challenge in many professions is plagiarism. Simon [2] states that there is no definite definition of academic integrity that is universally accepted; however, any work presented for credit is presumed to solely be the work of the presenter/ is presumed to be the work solely of the presenter. Starovoytova and Namango[3] summarize the meaning of plagiarism as the practice of taking or slightly altering the intellectual property of another person's "work, ideas, data, graphs, tables, figures, spoken-words, graphics, music, photos, poetry, art, audio-clips, and videos from various-media sources, among others," and passing this work off as one's own, without appropriate or adequate recognition or citation. Economou[4] claims that plagiarism is an intention to conceal the source material. This definition sets plagiarism apart from pastiche, where there is no intention to conceal or reveal, and from parody, which intentionally reveals the source material.

Plagiarism has long been a significant issue for researchers and educators alike; academic misconduct among university students has been investigated as early as 1964 [5]. Before the 1990s, plagiarism was limited to printed sources and was difficult to accomplish because it involved copying text by hand. At present, however, it is easy to access and copy a large set of data through the Internet [3]. Therefore, incidences of and chances for 
committing plagiarism are more common. It is important that students do not become professionals without first having a clear understanding of what amounts to plagiarism, the ills associated with it, and ways to avoid it.

Plagiarism studies have been conducted in various disciplines in the realm of higher education. The field of art and design considers visual images as the final output of work; as Bettaieb[6] acknowledges, interior design students express their ideas through drawings or modeling during practical application and production. Interior design is the application of science and art for augmenting the interior of a building to make the space more aesthetic, and yet practical. An interior designer is, thus, involved in planning, researching, customizing, and managing such ventures. Therefore, plagiarism in this field is comprehensive and sophisticated, extending beyond the verbatim copying of written words, with easy access and open sources that provide full details of interior design projects. As a project encompasses the conceptual and visual ideas that result from studying, in-depth research, and designer experience, copying the ideas of other designers may amount to the plagiarism of ideas; this has a negative impact on the designer, society, and the interior design field. Alawad et al.[7] state that the spread of the phenomenon of plagiarism in the field of interior design prevents original ideas and creative solutions from fulfilling client's needs, while also encouraging students to repeat previous ideas, resulting in a lack of innovation in their design projects. As a result, D'Anjou[1] stated that design ethics are not only related to large scale problems but also to the daily practices of designers at all levels and in all aspects of design. Hence, plagiarism can occur in a designer's daily practices, consciously or unconsciously. Therefore, this study aimed to identify students' attitudes towards plagiarism in the interior design field. Through distribution of a questionnaire among interior design students, it evaluated the students' responses along several axes: students' knowledge and comprehension of concepts regarding plagiarism, identifying the causes of plagiarism, and identifying the project phases in which plagiarism generally occurs.

\subsection{The Problem of Visual Plagiarism}

Over the last few years, the higher education sector has increased its awareness of the growing incidences of plagiarism [3,4,8-14]. There has been considerable investment on the part of universities to detect text plagiarism. However, in the field of visual arts, little has been done to detect visual plagiarism. While some studies about plagiarism in the field of design and creative arts have been conducted, and each had a different aim $[3,4,8-13,15]$. Several computer programs detect text plagiarism, such as iThenticate and Turnitin. However, artwork, such as a sketch of a boardroom desk, cannot be adequately assessed using traditional identification software. Though Garrett and Robinson[12] introduced the iTrace visual search tool and mentioned that there are additional tools, such as Tineye and Google Image Search. It is worth noting that their application with respect to the issue of visual plagiarism has not received adequate testing. The dilemma of visual plagiarism is particularly profound in the field of interior design.

Porter[16] states that academic misconduct in the creative field may be more difficult to identify and discover than in cases of textual work. In addition, Simon et al.[11] found notable variations in the degree of the perception of plagiarism between textual and non-textual content with regard to design assessments. Researchers have agreed that there is a general lack of clarity regarding the boundaries between plagiarism and ethical research. An essential step in reducing plagiarism is teaching staff and students to recognize its different forms, with an emphasis on the less obvious ones [3,11-14,16]. While studies on plagiarism present multiple motives for student's plagiarism in different disciplines, there is a scarcity of research in the field of art and design. Furthermore, in other disciplines, as Economou[4] states, there are many comprehensive guides available to students and teachers that provide practical information on how to appropriately refer to sources and avoid plagiarism. However, in creative areas, especially visual arts, there does not seem to be a comprehensive and up-to-date equivalent[4].

Noha et al.[10] states that the rate of visual plagiarism in art and design programs is alarming. Therefore, academics should consider visual plagiarism to be a major offense to help prevent the issue from spreading within the academic community and, ultimately, in professional practice. According to Economou[4], evidence suggests that without comprehensive assistance for visual arts students, lecturers rely on policy and procedure documents. These types of documents include broad visual representation, but do not provide enough educational opportunities and ideas for students to identify and avoid plagiarism. As Coorey[8] stipulates, an educator in the field of design needs to define plagiarism from the perspective of the design discipline. Researchers believe that the effective education and training of art and design students will help them in their professional practice $[6,16]$. Keeping this in mind, the research must focus on teaching and training students in specialization, creativity, and innovation, so that they do not practice plagiarism.

Many researchers have provided recommendations to help prevent incidences of plagiarism in the field of art and design. Economou[4 proposes some suggestions, such as documenting policies, giving lectures to students about visual plagiarism, and providing practice for students regarding indicating sources in their work.

Moreover, Garrett and Robinson[12] suggest that further work is required to help students understand how 
to locate and reference sources properly; there should also be a system in place to track the impact of visual resources. Simon et al.[11] argue that clear definitions of and differences between plagiarism and collusion with regard to design assessments should be established, which should be incorporated in academic integrity policies; furthermore, educational strategies that seem appropriate for academics and students should be implemented. However, Mostafa[13] proposes that some creative disciplines such as art and design may require a different list of definitions, standards, and practices. In addition to having a plan to educate students about the current and future risks of plagiarism, Al-Awad et al.[15] recommend having a guide that clarifies the meaning of all types of plagiarism in the field of interior design. They also suggest that the academic tutors should see students' previous work, so that they can follow students' development and point them in the right direction.

Simon[11] states that there should be some agreement regarding the practices that are appropriate in a particular discipline, which would make it easier to identify breaches of academic integrity. Blythman et al.[14] recommend a discussion between academic staff and students regarding copying and plagiarism problems; further, they suggest developing educational strategies and assessing them by using tactics that divide projects into chunks, as well as giving feedback and guidance to assist students in the development of their own ideas.

It is evident from previous literature that plagiarism has been in existence for a long time. Although many studies have researched text plagiarism, there are relatively few studies in the field of design and creative arts, especially interior design. While the development of technology appears to have increased the ease with which plagiarism is committed, it has also provided programs that can detect visual plagiarism. Unfortunately, due to the complex process of interior design, more than one tool or method may be needed to detect plagiarism in a design project. Even though many researchers have made recommendations to help prevent plagiarism, discover its causes, and develop preventive strategies, visual plagiarism remains mostly untested, and much more in-depth research is required in the field. Considering all these limitations, the researcher believes that including the issue of plagiarism in the interior design curriculum will help both students and professionals to avoid it.

\subsection{Why Do Students Plagiarize?}

Researchers believe that there are specific reasons why students plagiarize, which are related to the particular field of study, along with common reasons among university students across fields. However, most researchers also agree that easy access to the Internet is the main facilitator of plagiarism $[3,4,12,13]$. Regarding the field of art and design, the Internet is full of visual images. Some researchers have found that a shortage of information on and understanding of plagiarism among students may make them more likely to plagiarize $[3,9,10]$. Time limitations and strict deadlines can also be a factor $[9,10]$.

Al-Awad et al.[15] mentioned some factors related to self-plagiarism and the repetition of work from the point of view of academics. These include students' fear of failure in new projects, which drives them to return to their previous well-received work, as well as students' commitment to a specific direction in design which they do not voluntarily change. In their study, Noha et al.[10] found that students were confused as to what the term "visual plagiarism" meant. Some were not aware that plagiarism is viewed as an offense in the world of academia. Several factors can cause students to plagiarize visual material, for example, mismanagement of time during the project, disregard of feedback from tutor's input sessions, or lack of appropriate referencing. However, according to Blythman et al.[14], the design staff they interviewed admitted that in the early stages of a project, students copy from other resources that they plan to use as a template for their own ideas; this seems to suggest that visual plagiarism is not as prevalent as text plagiarism.

As there is more than one reason a student might plagiarize, it is necessary to use different approaches to reduce plagiarism. One method cannot guarantee academic integrity in the field of art and design. Educators and researchers need to create, nourish, propagate, and support a culture against plagiarism. Academic integrity not only protects intellectual and creative property, but also facilitates learning and creativity. As Coorey[8] mentioned, the university's efforts to help students learn about visual plagiarism include visual ethics in curricula, lectures, and student discussions; however, despite these efforts, there are still cases of plagiarism among students. Students in the field of art and design, especially in interior design, tend to come up with multiple ideas and then choose the most appropriate one for a specific project. Therefore, if they have a shortage of information regarding plagiarism, or do not recognize it as an offense in the academic environment, they can plagiarize without meaning to. Noha et al.[10] state that running out of ideas in a critical period may be one of the reasons for plagiarism. Moreover, some students may believe that information found on the Internet is in the public domain and, thus, can be used freely without being flagged for plagiarism [3]. Furthermore, some researchers argue that one of the factors contributing to visual plagiarism is that students cannot distinguish it from creative inspiration $[8$, 13]. Student's lack of experience in the field is another contributing factor [4].

Additionally, cultures differ in their classification of plagiarism [16], and some societies are more sensitive to it than others. Thus, the students' background should be 
considered, particularly in the case of international students. A reason for its pertinence could stem from the methods used in school settings to teach art education. For example, Japanese students spend most of their elementary and middle school art classes sketching. This may lead them to view drawing as solely a matter of representing objects in real life [17]. It is also known that inspiration is the starting point for new design work and that one can either be inspired by nature or the work of others. Several researchers and writers, such as D'Anjou[1], mentioned that each discipline has its specificity in judging the integrity of the work. Copying the work of others has another ruling, as if the copied work belongs to an individual or a cultural identity. In the case of interior design, the situation is different because it depends on many considerations, including the type of project, the client's requirements, and the designer's experience. Here, copying is considered plagiarism because the design ideas are the property of the original designer and are the products of research, creative thinking, and experience.

Richardson's[18] experiment with twenty senior graphic design students at Eastern Illinois University revealed that giving students room and flexibility to fail and to "fail big" helped them learn. He concluded that if there is not enough room to fail, students often take the safe and secure route in their concepts and design, which can include or lead to plagiarism. Does this then mean that teaching strategies and styles need to be reviewed? Is it possible that current strategies drive students to plagiarize? Though researchers have agreed upon the general causes of plagiarism, each field has its own contributing factors. Determining what these are will help teachers and students develop better and more precise measures to combat plagiarism.

\section{Materials and Methods}

This study was conducted in the Interior design and Furniture Department, Faculty of Human Sciences and Design, at King Abdulaziz University, Saudi Arabia. It was carried out in the second semester of the 2019 academic year.

\subsection{Sample}

A questionnaire was distributed to interior design and furniture students from all levels in the academic year, with a total of 92 full-time students in the program. There were 59 respondents, which equated to $64.13 \%$. All students had already participated in different types of projects and research tasks and were, therefore, sufficiently familiar with the subject. The researcher explained that their responses would be anonymous and used for research purposes only.

\subsection{Course Workflow}

The interior design program is considered to be a practical, scientific specialization. The number of academic years ranges between four and five years, according to university policies and the number of program hours. The curriculum contains theoretical and practical subjects. The Interior Design Studio is the basis for teaching interior design, where, according to the academic level, real-world implementation is practiced for different projects. Al-Awad et al.[15] analyzed a number of interior design program study plans in Saudi Arabia. They stated that these programs hone students' knowledge and competencies in the elements and principles of design, theories, as well as concepts of interior design; in addition to creative and critical thinking abilities, they also hone manual and architectural drawing skills. Furthermore, there is diversity and inclusion of residential, administrative, commercial, and tourism aspects in the projects of the Interior Design Studio. Local identity and professional ethics are part of the program. It provides creative solutions to design problems, considering internal and international standards, as well as cultural and social differences, laws, policies, and environmental resources [15]. Interior design projects go through many basic stages, along with several steps and procedures that require special knowledge and skills [19]. Bettaieb[6] states that interior design students, especially in the early stages, learn design elements and principles, as well as design methods to apply during practical application, such as drawing or modeling. Therefore, students learn the theory of design and gain inspiration from a range of different materials.

All these stages require knowledge and skills in the field, along with great professional ethics to tackle projects. Designers need to be aware of new projects and may be inspired by them; however, they can also copy them by mistake. It is the role of the educator to teach and highlight this issue to the students.

\subsection{Questionnaire}

The questionnaire was developed, based on relevant literature, through analyzing the meaning and causes of plagiarism. It was created by the researcher and divided into three axes. After basic information like age, level of study, and so on, the first axis measured students' knowledge and understanding of the concept of plagiarism, its application, and its impact. The second axis aimed to identify the causes of plagiarism among interior design students, such as personal reasons, the university system, teaching methods, or social influences. The third axis attempted to identify the phase of the project in which plagiarism occurred. The five-point Likert scale questionnaire consisted of a total of 42 questions. The Statistical Packages for the Social Sciences (SPSS) software was used to analyze the data, and the results 
obtained are shown in Table 1.

The frequency distribution and percentages presented in Table 1 are shown in Figure 1.

The questionnaire was presented to three academics in the interior design field who suggested a few corrections to the statements, such as shortening and clarifying some long phrases. Thereafter, the Pearson correlation coefficient was used to measure the relationship of each question to the axes, as shown in Table 2. In addition, the results of the questionnaire were confirmed through the work of a focus group of five students, which validated the data presented in the questionnaire.

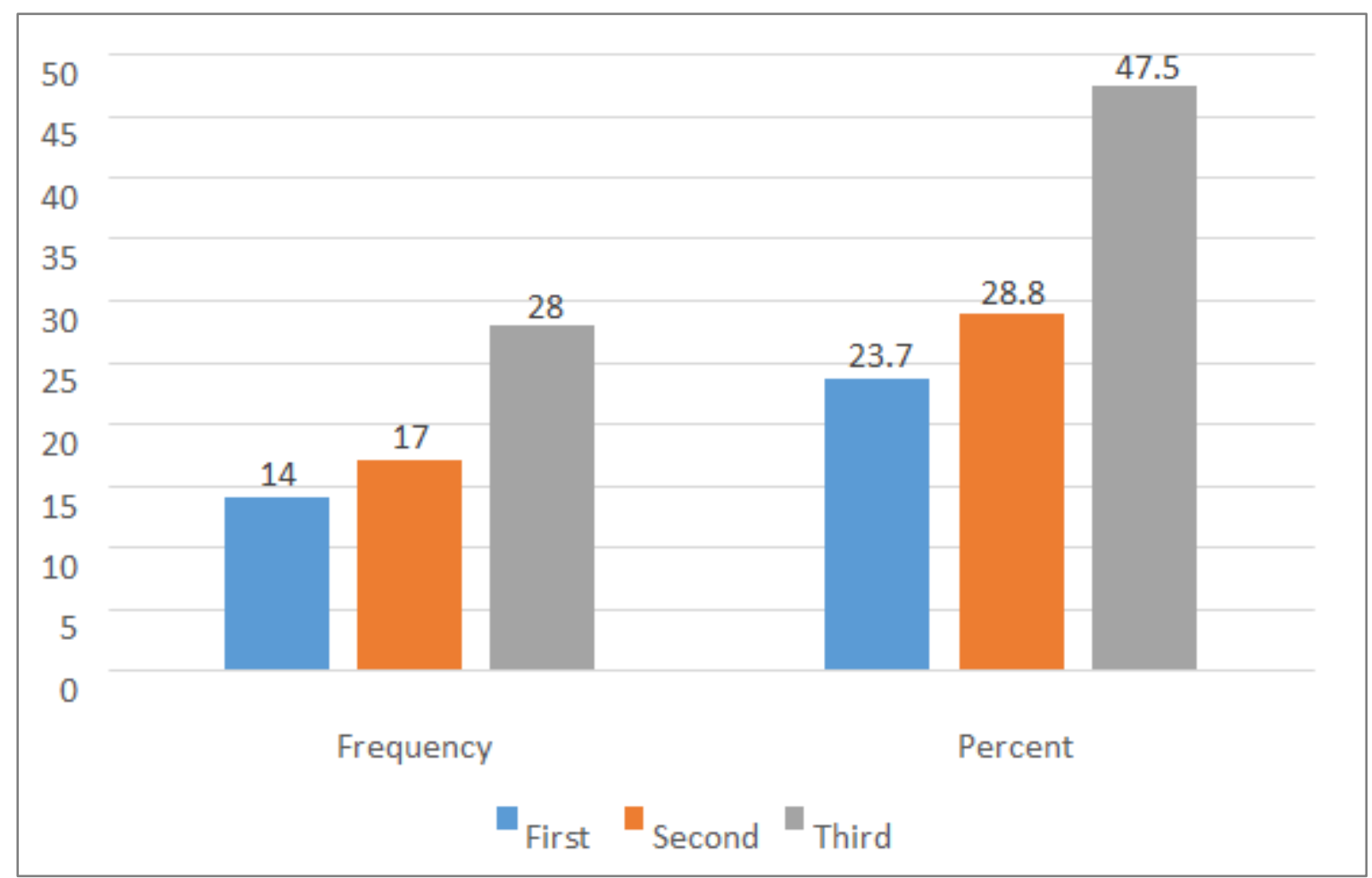

Figure 1. Summary of frequency percentage graph

Table 1. The distribution of the sample of interior design students according to the year of study

\begin{tabular}{|c|c|c|}
\hline Year of Study & Frequency & Percent \\
\hline First & 14 & 23.7 \\
\hline Second & 17 & 28.8 \\
\hline Third & 28 & 47.5 \\
\hline
\end{tabular}


Table 2. Correlation coefficients of each question to the axis

\begin{tabular}{|c|c|c|c|c|}
\hline Axes & Statement & $\begin{array}{c}\text { Correlation } \\
\text { coefficient** }\end{array}$ & Statement & $\begin{array}{l}\text { Correlation } \\
\text { coefficient** }\end{array}$ \\
\hline \multirow{8}{*}{$\begin{array}{l}\text { Measuring students' } \\
\text { knowledge and } \\
\text { comprehension of } \\
\text { concepts regarding } \\
\text { plagiarism }\end{array}$} & 1 & 0.687 & 9 & 0.649 \\
\hline & 2 & 0.686 & 10 & 0.666 \\
\hline & 3 & 0.608 & 11 & 0.519 \\
\hline & 4 & 0.683 & 12 & 0.690 \\
\hline & 5 & 0.583 & 13 & 0.574 \\
\hline & 6 & 0.681 & 14 & 0.476 \\
\hline & 7 & 0.561 & 15 & 0.507 \\
\hline & 8 & 0.589 & 16 & 0.595 \\
\hline \multirow{8}{*}{$\begin{array}{l}\text { Identifying the causes of } \\
\text { plagiarism among interior } \\
\text { design students }\end{array}$} & 1 & 0.782 & 9 & 0.826 \\
\hline & 2 & 0.702 & 10 & 0.760 \\
\hline & 3 & 0.697 & 11 & 0.582 \\
\hline & 4 & 0.634 & 12 & 0.672 \\
\hline & 5 & 0.605 & 13 & 0.489 \\
\hline & 6 & 0.709 & 14 & 0.404 \\
\hline & 7 & 0.828 & 15 & 0.461 \\
\hline & 8 & 0.844 & NA & NA \\
\hline \multirow{6}{*}{$\begin{array}{l}\text { Identifying the project } \\
\text { phases in which } \\
\text { plagiarism generally } \\
\text { occurs }\end{array}$} & 1 & 0.538 & 7 & 0.804 \\
\hline & 2 & 0.420 & 8 & 0.789 \\
\hline & 3 & 0.592 & 9 & 0.768 \\
\hline & 4 & 0.851 & 10 & 0.818 \\
\hline & 5 & 0.589 & 11 & 0.571 \\
\hline & 6 & 0.603 & NA & NA \\
\hline
\end{tabular}

It is clear from Table 2 that all correlation coefficients between the terms and their associated axes were positive and statistically significant at a level below 0.01 .

Cronbach's alpha was used to test the reliability of the questionnaire in achieving its intended goal. The results are shown in Table 3 below.

Table 3. Values of Cronbach parameters for the resolution axes

\begin{tabular}{|c|c|}
\hline Axes & Cronbach's alpha \\
\hline $\begin{array}{c}\text { Students' knowledge and understanding of } \\
\text { plagiarism }\end{array}$ & 0.879 \\
\hline Causes of plagiarism & 0.908 \\
\hline When plagiarism occurs & 0.874 \\
\hline
\end{tabular}

The results in Table 3 show the values of the Cronbach parameters for the resolution axes. Cronbach's alpha values for students' knowledge and understanding of plagiarism, causes of plagiarism, and when plagiarism occurs were $0.879,0.908$, and 0.874 , respectively. This reflected positively on the results of this study, that is, the questionnaire achieved the goals that were set. In Table 4, the following staging was used to classify the mean responses at each level of understanding:

Table 4. The range of phrases for each level of understanding

\begin{tabular}{|c|c|}
\hline Mean & Level \\
\hline$<1.80$ & Very small \\
\hline From 1.81 to $<2.60$ & Small \\
\hline From 2.61 to $<3.40$ & Moderate \\
\hline From 3.41 to $<4.20$ & Large \\
\hline
\end{tabular}

\section{Results and Discussion}

Three axes were outlined in the questionnaire regarding visual plagiarism according to students' perceptions: students' knowledge and understanding of the topic, causes of plagiarism, and when plagiarism typically occurs during a project. To measure the first axis, the mean and standard deviations of the respondents' answers were calculated based on their level of knowledge and understanding of the concept of plagiarism. The results of the same are shown in Table 5 given below. 
Table 5. Mean and standard deviations of responses indicating student comprehension of plagiarism concepts

\begin{tabular}{|c|c|c|c|c|}
\hline No. & Statement & Mean & SD & Level \\
\hline 2 & Plagiarism is bad behavior. & 4.75 & 0.779 & Very Large \\
\hline 10 & Plagiarism kills creativity. & 4.54 & 0.877 & Very Large \\
\hline 12 & $\begin{array}{c}\text { Plagiarism is taking another designer's words, ideas, and work without } \\
\text { citation. }\end{array}$ & 4.54 & 0.877 & Very Large \\
\hline 4 & $\begin{array}{l}\text { Plagiarism is not allowed in published work, but in unpublished work, it is ok } \\
\text { to use sources without citation. * }\end{array}$ & 4.44 & 0.836 & Very Large \\
\hline 5 & $\begin{array}{l}\text { Plagiarism of another designer's work does no harm in the field of interior } \\
\text { design. * }\end{array}$ & 4.42 & 0.969 & Very Large \\
\hline 3 & $\begin{array}{l}\text { It is not considered plagiarism if I copy an idea or two from other people's } \\
\text { work without citation. * }\end{array}$ & 4.39 & 0.929 & Very Large \\
\hline 9 & Plagiarism breaks academic integrity. & 4.34 & 1.010 & Very. Large \\
\hline 1 & There is no plagiarism in the field of interior design. * & 3.85 & 1.096 & Large \\
\hline 6 & I have plagiarized at least once in my work. ${ }^{*}$ & 3.76 & 1.150 & Large \\
\hline 14 & It is possible to hire a specialist to do my project. * & 3.71 & 1.260 & Large \\
\hline 13 & Sometimes, I use another designer's work without citing the source. * & 3.68 & 0.990 & Large \\
\hline 7 & Someone has plagiarized my work. * & 3.49 & 1.104 & Large \\
\hline 15 & $\begin{array}{l}\text { It is not considered plagiarism when I make some modifications to another } \\
\text { designer's work. * }\end{array}$ & 3.34 & 1.108 & Moderate \\
\hline 11 & Plagiarism is taking just the words of other designers without citation. & 3.07 & 1.363 & Moderate \\
\hline 16 & I use professional design websites heavily in my work. ${ }^{*}$ & 2.64 & 0.996 & Moderate \\
\hline \multirow[t]{2}{*}{8} & Self-plagiarism is not considered plagiarism. $*$ & 2.54 & 1.236 & Small \\
\hline & Total & 3.84 & 0.625 & Large \\
\hline
\end{tabular}

* Negative phrase

Table 5 shows that statement 2 ("Plagiarism is bad behavior") had the highest average, with a mean value of 4.75 and a significant degree of approval; on the other hand, statement 8 ("Self-plagiarism is not considered plagiarism") had the lowest average with a mean value of 2.54 and a low degree of approval. It is also clear that, while students understand the general meaning of plagiarism, they are confused about some of the details regarding it. In this sense, the findings of this study are in agreement with those of Baysen et al.[9], Starovoytova and Namango[3], and Noha et al.[10]. This finding is also not surprising because King Abdulaziz University is working hard to explain the issue of plagiarism to the students and staff by training them and offering related software. However, regarding the interior design field, it is the responsibility of the department to clarify the unique details related to the plagiarism of interior design material to the students.

Table 5 also shows that the total number of phrases reached an average of 3.84 and a high degree of approval, indicating that the level of student knowledge and understanding of the concept of plagiarism was very high.

The second axis attempted to identify the causes of plagiarism among interior design students, such as personal reasons, the university system, teaching methods, or social influences. To evaluate this, the mean and standard deviations of respondents' answers were calculated with respect to the causes of plagiarism. The results of the same are given in Table 6.

Table 6 shows that statements $11,5,14,6$, and 15 had a moderate score; statement 11 ("Sometimes, I use an idea or two from another designer's work to inspire me") had the highest calculated mean (3.20). While the rest of the phrases obtained a few degrees of approval, statement 13 ("When I do not know what to write in a design concept, I translate a part of another designer's work from a foreign language") had the lowest degree of approval; it also obtained the lowest average, with a mean value of 1.88 . 
Table 6. Mean and standard deviations of the respondents' scores on the causes of plagiarism

\begin{tabular}{|c|c|c|c|c|}
\hline No. & Statement & Mean & SD & Level \\
\hline 11 & $\begin{array}{l}\text { Sometimes, I use an idea or two from another designer's work to } \\
\text { inspire me. }\end{array}$ & 3.20 & 0.906 & Moderate \\
\hline 5 & $\begin{array}{l}\text { Sometimes, I use another designer's work and I forget to cite the } \\
\text { source. }\end{array}$ & 3.14 & 1.074 & Moderate \\
\hline 14 & $\begin{array}{l}\text { If I find the same ideas that I have been thinking about, it is justifiable } \\
\text { to copy these ideas without referring to the source. }\end{array}$ & 2.88 & 1.146 & Moderate \\
\hline 6 & $\begin{array}{l}\text { Sometimes, I use another designer's work without citation because I } \\
\text { do not understand the assignment. }\end{array}$ & 2.80 & 1.047 & Moderate \\
\hline 15 & $\begin{array}{l}\text { It is not considered plagiarism if my colleague allows me to copy } \\
\text { from their work. }\end{array}$ & 2.73 & 1.157 & Moderate \\
\hline 9 & $\begin{array}{c}\text { Sometimes, I use another designer's work without citation because I } \\
\text { have limited time. }\end{array}$ & 2.56 & 1.103 & Small \\
\hline 8 & $\begin{array}{c}\text { Sometimes, I use another designer's work without citation as my own } \\
\text { ideas have been depleted. }\end{array}$ & 2.46 & 1.119 & Small \\
\hline 3 & $\begin{array}{c}\text { Sometimes, I use another designer's work without citation because } \\
\text { there are no regulations or policies on plagiarism in the field of } \\
\text { interior design. }\end{array}$ & 2.42 & 1.206 & Small \\
\hline 1 & $\begin{array}{l}\text { Sometimes, I use another designer's work without citation because } \\
\text { everyone else is doing it. }\end{array}$ & 2.32 & 0.990 & Small \\
\hline 7 & $\begin{array}{l}\text { Sometimes, I use another designer's work without citation to gain a } \\
\text { good grade. }\end{array}$ & 2.24 & 0.971 & Small \\
\hline 2 & $\begin{array}{c}\text { Sometimes, I use another designer's work without citation because I } \\
\text { have not been caught or guided. }\end{array}$ & 2.17 & 1.101 & Small \\
\hline 4 & $\begin{array}{l}\text { Sometimes, I use another designer's work without citation because it } \\
\text { is in the public domain and accessible. }\end{array}$ & 2.15 & 0.979 & Small \\
\hline 10 & Plagiarism is justified if I have many tasks to do. & 2.05 & 0.899 & Small \\
\hline 12 & $\begin{array}{l}\text { Sometimes, I use another designer's work without citation because I } \\
\text { am a fan of their work. }\end{array}$ & 2.00 & 0.851 & Small \\
\hline \multirow[t]{2}{*}{13} & $\begin{array}{c}\text { When I do not know what to write in a design concept, I translate a } \\
\text { part of another designer's work from a foreign language. }\end{array}$ & 1.88 & 0.832 & Small \\
\hline & Total & 2.47 & 0.683 & Small \\
\hline
\end{tabular}

Furthermore, Table 6 shows that the expressions had a mean of 2.47 and a low degree of approval in total. This observation indicates that only statements $11,5,14,6$, and 15 represent the causes of plagiarism. Despite the many options given to the students as potential reasons to plagiarize, only five represent the actual causes of plagiarism; these include accidental plagiarism and other instances that arise out of good intentions such as drawing inspiration, forgetting to cite a source, finding the same ideas that they were thinking about in another work, or not understanding the topic. Students stated that they need to garner inspiration from other works, which supports studies of researchers who have proposed that students use visual inspiration to create their own repertoire $[8,16]$ and those who have asserted that students cannot distinguish between creative inspiration and plagiarism [8].

The third axis tries to identify when plagiarism tends to occur in a project. To evaluate this, the mean and standard deviations of respondents' answers were calculated based on the project phases. The results of the same are shown in Table 7.

Table 7 shows that statements 2 and 7 had moderate scores, the higher of which was for statement 2 ("If I find an already published initial design study, it is justifiable to copy it without citation to avoid time delays"), with a mean of 2.80. While the rest of the phrases obtained a few degrees of approval, statement 11 ("If I find the same project already published, it is justifiable to copy it without citation to avoid time delays") had the lowest degree of approval, with a mean value of 1.73 . 
Table 7. Mean and standard deviations of respondents' scores to identify the project phase in which plagiarism occurs

\begin{tabular}{|c|c|c|c|c|}
\hline No. & Statement & Mean & SD & Level \\
\hline 2 & $\begin{array}{c}\text { If I find an already published initial design study, it is justifiable to copy it } \\
\text { without citation to avoid time delays. }\end{array}$ & 2.80 & 1.141 & Moderate \\
\hline 7 & $\begin{array}{l}\text { If I am not successful in choosing furniture unit styles and layout, it is justifiable } \\
\text { to copy this part of a similar project that is already published without citation. }\end{array}$ & 2.73 & 1.048 & Moderate \\
\hline 9 & $\begin{array}{l}\text { If I am not successful in choosing lighting distribution, it is justifiable to copy } \\
\text { this part of a similar project that is already published without citation. }\end{array}$ & 2.47 & 1.088 & Small \\
\hline 10 & $\begin{array}{c}\text { If I am not successful in choosing furniture unit styles and layout, it is justifiable } \\
\text { to copy a similar part of a similar project that is already published without } \\
\text { citation. }\end{array}$ & 2.41 & 1.019 & Small \\
\hline 8 & $\begin{array}{l}\text { If I am not successful in choosing materials and ratios among materials, it is } \\
\text { justifiable to copy a similar part of a similar project that is already published } \\
\text { without citation. }\end{array}$ & 2.39 & 1.067 & Small \\
\hline 4 & $\begin{array}{c}\text { If I cannot draw my initial ideas at the first stage, it is justifiable to copy a similar } \\
\text { part of a similar project that is already published without citation. }\end{array}$ & 2.34 & 0.958 & Small \\
\hline 6 & If I find a floor plan, it is justifiable to copy it without citation. & 2.29 & 1.018 & Small \\
\hline 5 & $\begin{array}{c}\text { Sometimes, I make a wrong decision in a design concept, which has a difficult } \\
\text { application; therefore, I use another designer's work without citation to } \\
\text { complete the work. }\end{array}$ & 2.27 & 1.064 & Small \\
\hline 1 & I could not do a full project without some type of copying. & 2.20 & 0.996 & Small \\
\hline 3 & $\begin{array}{l}\text { In group discussions, I can take colleagues' ideas and implement them in my } \\
\text { work. }\end{array}$ & 1.90 & 0.959 & Small \\
\hline \multirow[t]{2}{*}{11} & $\begin{array}{l}\text { If I find the same project already published, it is justifiable to copy it without } \\
\text { citation to avoid time delays. }\end{array}$ & 1.73 & 0.739 & $\begin{array}{l}\text { Very } \\
\text { small }\end{array}$ \\
\hline & Total & 2.32 & 0.674 & Small \\
\hline
\end{tabular}

Moreover, Table 7 shows that the expressions had a mean of 2.32 in total, along with a low degree of approval. This result indicates that statements 2 and 7 represent the phases in which plagiarism mostly occurs; this happens during the initial design phase and when choosing the color scheme. For the researcher, this does not count as plagiarism because the projects are not the same, and inspiration is drawn only during the initial phases. Each project has its own aim, brief, and guidelines, but by looking at other project design studies, students gain guidance and inspiration. In terms of color schemes, many programs show ideal color schemes and combinations. Further, some color factories provide services that help students generate color schemes. These results confirm the assertion of Blythman et al.[14], that using other people's work is acceptable if, and only if, it is used as a starting point for one's own vision. They argue that this is not only acceptable, but inevitable. The students' responses in this study confirm this.

Finally, the data of the questionnaire was validated through a focus group; it was found that the result of the discussion with the group matched the findings of the study.

\section{Conclusions}

This study has shown that students understand the general meaning of plagiarism, but are confused about its specific application to the discipline of interior design.
Therefore, educators in this field should explain plagiarism in detail to their students to make sure they understand the concept and how it relates to their subject. Visual plagiarism is difficult to define and depends on different considerations according to the design process. However, it can be claimed that repetitive work without any development that does not add value and is copied from existing work without citation constitutes plagiarism.

According to the aforementioned, it is evident that inspiration is important for the interior designer, whether it is drawn from nature or from the works produced by humans. Also, despite all the reasons taken into consideration in the study, it was found that only five reasons represented the actual causes of plagiarism. Thus, educators should explain the creative process and identify the fine line between inspiration and plagiarism, confirm that students cite other works, and ensure that all students understand the topic before they start the project.

This research will help in gaining a better understanding of plagiarism among interior design students; it will also act as the first step towards addressing the problem of plagiarism in a preventive manner, rather than a punitive one. Hopefully, this methodology will help in the development of curricula and delivery approaches to improve students' working processes and awareness of plagiarism. Ultimately, the aim is to reduce incidences of plagiarism, to ensure academic integrity among students in the field of interior design, as well as to foster creativity rather than stifle it. Students graduating with unambiguous concepts of 
plagiarism are likely to avoid committing it, intentionally or unintentionally, in their professional lives.

The limitations of this study are that the results cannot be generalized because they are based on a relatively small number of self-reports by students in one institution. Nonetheless, the results provide information about a new practice that may reduce the number of plagiarism incidents in the field of interior design. It is worth noting that some of the results that have been recorded can be applied in other fields of design and creative arts due to their many similarities.

For further research, it would be helpful to study students' perceptions of the difference between inspiration and visual plagiarism, as well as the difference between text and visual plagiarism.

\section{REFERENCES}

[1] P. D'Anjou. Ethical Design Intelligence: The Virtuous Designer, Routledge, U.K., 2020.

[2] B. C. Simon. Academic Integrity in Non-Text Based Disciplines, Handbook of Academic Integrity, Springer Science and Business Media, Singapore, 2015. DOI: 10.1007/978-981-287-079-7.

[3] D. Starovoytova, S. S. Namango. Viewpoint of undergraduate engineering students on plagiarism, Journal of Education and Practice, Vol.7, No.31, 48-65, 2016.

[4] I. Economou. The Problem with Plagiarism, Sixth International the Design Education Forum of Southern Africa Conference (DEFSA 2011) 79-86, 2011.

[5] S. J. Howard, J. F. Ehrich, R. Walton. Measuring students' perceptions of plagiarism: Modification and Rasch validation of a plagiarism attitude scale, Journal of Applied Measurement, Vol.15, No.4, 372-393, 2014.

[6] D. M. Bettaieb. Proposed strategy in teaching design fundamentals for understanding the relationship between idea and idea's projection, Art and Design Review, Vol.5, No.2, 129, 2017.

[7] A. Alawad, D. Bettaieb, R. Malek. Self-plagiarism in students' interior design projects from an academic perspective, International Journal of Management, Vol.11, No.10, 1370-1382, 2020. DOI: 10.34218/IJM.11.10.2020.1
23

[8] J. Coorey. Removing plagiarism from the design process: Stimulating creativity and originality in the design classroom, The International Journal of Design Education, Vol.12, No.1, 11-19, 2018.

[9] F. Baysen, N. Çakmak, A. Özsavas Akcay. Architecture students' attitudes toward plagiarism, Information World/Bilgi Dunyasi, Vol.19, No.2, 232-253, 2018.

[10] M. Noha, A. Nudinb, N. Abdullahb, W. Shamsudin, F. Harun. Plagiarism in Graphic Design, 2nd Art and Design International Conference (AnDIC 2016), 391-400, 2016.

[11] B. C. Simon, M. Minichiello, C. Lawrence. Academic Integrity: Differences between Design Assessments and Essays, Design Research Society Conference (DRS 2014), 2014.

[12] L. Garrett, A. Robinson. Spot the Difference! Visual Plagiarism in the Visual Arts, Electronic Visualization and the Arts Conference (EVA, 2012), 24-33, 2012.

[13] M. Mostafa. Inspiration versus plagiarism: Academic integrity in architectural education, International Journal of the Constructed Environment, Vol.1, No.3, 85-99, 2011.

[14] M. Blythman, S. Orr, J. Mullin. Reaching a Consensus: Plagiarism in Non-Text Based Media, London College of Communication, University of the Arts London, London, 2007, Online available from http://www.jiscpas.ac.uk/case studies.php.

[15] A. A. Alawad, R. S. Bazuhair, R. A. Alhojaly, M. M. Mossawa. The compatibility of higher education outcomes with the requirements of the labour market in an interior design programme in the Kingdom of Saudi Arabia, Art and Design Review, Vol.8, No.2, 94-113, 2020. DOI: 10.4236/adr.2020.82007.

[16] M. Porter. A Consideration of academic misconduct in the creative disciplines: From inspiration to imitation and acceptable incorporation, Emerge, Vol. 2, 1-16, 2010.

[17] K. Ishibashi, T. Okada. How copying artwork affects students' artistic creativity, Proceedings of the Annual Meeting of the Cognitive Science Society, Vol.26, No.26, 618-623, 2004.

[18] D. Richardson. More Room to Fail. Or, 'All Work can be Resubmitted at the End of the Semester,' The Annual UCDA Design Education Summit, 33, 2014.

[19] D. Bettaieb, A. Alawad. Interior design, professional practice and competency requirements, International Design Journal, Vol.6, No.2, 101-108, 2016. 